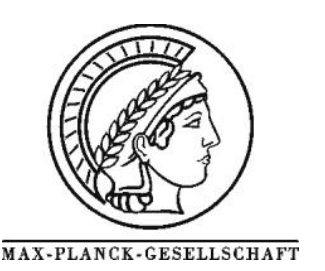

\title{
Structure and properties of a Mo oxide catalyst supported on hollow carbon nanofibers in selective propene oxidation
}

\author{
T. Ressler ${ }^{* 1}$, A. Walter ${ }^{1}$, J. Scholz ${ }^{1}$, J.-P. Tessonnier ${ }^{2}$, D. S. Su ${ }^{2}$
}

${ }^{1}$ Institut für Chemie, Technische Universität Berlin, Strasse des 17. Juni 135, 10623 Berlin, Germany

${ }^{2}$ Fritz-Haber-Institut der Max-Planck-Gesellschaft, Departement of Inorganic Chemistry, D-14195 Berlin, Germany

* Corresponding author: e-mail Thorsten.ressler@ @u-berlin.de,

Received 2 November 2009; revised 2 February 2010; accepted 3 February 2010. online 16 March 2010.

\begin{abstract}
In situ X-ray absorption spectroscopy (XAS) under reaction conditions of selective propene oxidation was employed to elucidate the local structure of as-prepared and activated molybdenum oxide supported on hollow vapor-grown carbon nanofibers (VGCNF). The local structure of asprepared $\mathrm{Mo}_{x} \mathrm{O}_{y}$-VGCNF was very similar to that of hexagonal $\mathrm{MoO}_{3}$. During heat treatment in propene- and oxygen-containing atmosphere, asprepared $\mathrm{Mo}_{x} \mathrm{O}_{y}$-VGCNF transforms into activated $\mathrm{Mo}_{x} \mathrm{O}_{y}$-VGCNF above $623 \mathrm{~K}$. The local structure around the Mo centers in activated $\mathrm{Mo}_{x} \mathrm{O}_{y}$ VGCNF is similar to that of $\alpha-\mathrm{MoO}_{3}$. Temperature- and time-dependent XAS measurements showed a rapid transformation from hex-MoO $\mathrm{M}_{3}$ to $\alpha$ $\mathrm{MoO}_{3}$ supported on VGCNF under reaction conditions. Subsequently, the resulting activated $\mathrm{Mo}_{x} \mathrm{O}_{y}$-VGCNF catalyst exhibited a slowly increasing average oxidation state. The latter coincided with the formation of acrylic acid, which is hardly detectable during catalysis on regular, binary $\alpha-\mathrm{MoO}_{3}$. Moreover, activated $\mathrm{Mo}_{x} \mathrm{O}_{y}-\mathrm{VGCNF}$ is much more active in the selective oxidation of propene compared to $\alpha-\mathrm{MoO}_{3}$. The correlation between catalytic selectivity and average oxidation state as a result of suitable reduction-oxidation kinetics corroborates the importance of structural complexity rather than chemical complexity.
\end{abstract}

Keywords: Heterogeneous catalysis; Structure-activity relationships; EXAFS spectroscopy; X-ray absorption; Molybdenum; Oxides; Support; Carbon nanofibers; Selective oxidation; Propene

\section{Introduction}

Mixed oxide catalysts containing metals from group 5 or 6 of the Periodic Table are active in selective oxidation of propane to acrolein and acrylic acid [1-6]. Detailed studies on the correlations between structure and performance are required to reveal the role of catalyst structure and composition. The reduced chemical complexity of binary oxides makes them preferred model systems to distinguish between structural and compositional effects on catalytic performance. $\alpha-\mathrm{MoO}_{3}$ constitutes the room temperature stable modification with $\mathrm{Mo}(\mathrm{VI})$ centers in the highest oxidation state. Hence, $\alpha-\mathrm{MoO}_{3}$ would be the simplest binary model system available for studying structure-activity correlations. Detailed studies on the characteristic defect structure of $\alpha-\mathrm{MoO}_{3}$ under propene oxidation conditions revealed a slightly decreased average Mo valence caused by slow re-oxidation kinetics $[7,8]$. The latter is correlated with the formation of shear-structural defects in the layer structure of bulk $\alpha-\mathrm{MoO}_{3}$. However, $\alpha-\mathrm{MoO}_{3}$ exhibits only moderate activity in propene oxidation with rather poor selectivity toward acrolein or acrylic acid. Furthermore, other binary modifications of hexavalent molybdenum like hexagonal $\mathrm{MoO}_{3}$ are not stable under reaction conditions above $623 \mathrm{~K}$ and readily decompose to $\alpha-\mathrm{MoO}_{3}$ [9]. Similarly, binary bulk Mo oxides with average valences between 6.0 and 4.0 (like $\mathrm{Mo}_{4} \mathrm{O}_{11}, \mathrm{Mo}_{8} \mathrm{O}_{23}$, etc.) are oxidized to $\alpha-\mathrm{MoO}_{3}$ under selective oxidation conditions.

In order to modify the structure of binary molybdenum oxides while maintaining structural stability above $673 \mathrm{~K}$, supporting oxide species on various oxidic or carbonaceous supports is currently employed extensively by many researchers [10-13]. Supported binary metal oxides may exhibit particular metal oxide structures which are not 
stable and, thus, not available for investigations under reaction conditions. We have shown recently that hexagonal $\mathrm{MoO}_{3}$ supported on nanostructured $\mathrm{SiO}_{2}$ is stable under selective oxidation conditions up to $773 \mathrm{~K}$ [9]. Moreover, dispersed supported metal oxides simplify correlating the local structure around the metal centers with their catalytic performance. Distinguishing active metal centers at the surface from metal centers in the bulk of conventional oxide catalysts is no longer required. Here, we have employed hollow vapor-grown carbon nanofibers (VGCNF) as support material for binary molybdenum oxide species as selective oxidation catalysts. Carbon nanotubes and nanofibers are progressively employed as catalyst support for many reactions. Compared to other supports, they are chemically stable in most aggressive media, they show a high thermal conductivity and offer the possibility to chemically modify their surface [14]. These materials also exhibit less than a monolayer of oxygen, only present at the surface. Therefore, the characterization of supported transition metal oxide catalysts with techniques such as X-ray photoelectron spectroscopy (XPS) or electron energy loss spectroscopy (EELS) is significantly easier than when oxidic supports are used. In addition, as for carbon nanotubes, VGCNFs show a smooth surface and are quasi transparent under the beam of the transmission electron microscope (TEM). The morphological (sintering) as well as the structural (phase transition) changes occurring during the catalytic reaction can be easily accessed when investigating the spent catalyst.

Obtaining structure property relationships of supported metal oxide catalysts is not a simple task. It requires experimental techniques that permit in situ studies under relevant reaction conditions at a suitable time resolution. $\mathrm{X}$ ray absorption spectroscopy (XAS) is particularly suitable to study the supported catalysts under reaction conditions $[9,15,16]$. The electronic structure of the constituent metals in the oxide catalyst is obtained from analyzing the nearedge region of the absorption spectrum. Moreover, geometric structural parameters like coordination numbers, nearest neighbor distances, and disorder parameters may be determined by fitting suitable theoretical model structures to experimental spectra. Here, we have performed in situ XAS investigations of molybdenum oxide supported on carbon nanofibers. Our approach focused on elucidating both the local structure around the Mo centers in the asprepared and the activated model catalysts and the structural dynamics under changing reaction conditions.

\section{Experimental}

\subsection{Sample preparation}

Open, hollow vapor-grown carbon nanofibers (VGCNFs) were purchased from Pyrograf Products Inc., USA (Pyrograf-III, product PR24-PS). A detailed characterization of the pristine nanofibers is provided elsewhere
[17]. Briefly, the VGCNFs exhibit average internal and external diameters of 40 and $90 \mathrm{~nm}$, respectively, and lengths up to few hundred micrometers. The specific surface area of the VGCNFs was $43 \mathrm{~m}^{2} / \mathrm{g}$. The pristine nanofibers were functionalized with concentrated nitric acid $(65 \%)$ at $373 \mathrm{~K}$ for $16 \mathrm{~h}$ before use. Deposition of the molybdenum oxide was done by the incipient wetness impregnation technique using a solution of ammonium heptamolybdate $\left(\left(\mathrm{NH}_{4}\right)_{6} \mathrm{Mo}_{7} \mathrm{O}_{24} 4 \mathrm{H}_{2} \mathrm{O}\right.$, Fluka) with the acidity adjusted to $\mathrm{pH} 3$ with nitric acid. The concentration of the solution was set so the final metal loading of $7 \mathrm{wt} . \%$ Mo (10 wt.\% on a $\mathrm{MoO}_{3}$ basis). After deposition, the sample was dried at room temperature for $10 \mathrm{~h}$ and at $373 \mathrm{~K}$ for $5 \mathrm{~h}$ and subsequently calcined at $623 \mathrm{~K}$ for $2 \mathrm{~h}$. The resulting material is denoted as $\mathrm{Mo}_{x} \mathrm{O}_{y}-\mathrm{VGCNF}$, material treated at temperatures above $623 \mathrm{~K}$ is denoted as activated $\mathrm{Mo}_{x} \mathrm{O}_{y}$-VGCNF. Sample preparation and characterization have been described in detail in Ref. [18]. Electron microscopy studies revealed a disordered $\mathrm{Mo}_{x} \mathrm{O}_{y}$ layer on the surface of the VGCNF with a thickness of about $1 \mathrm{~nm}$. Distinct Mo oxide phase or particles of molybdenum oxides were detected neither in the as-prepared nor in the spent $\mathrm{Mo}_{x} \mathrm{O}_{y}$-VGCNF catalyst. Additionally, no crystalline Mo oxide phases were detected in the as-prepared and spent $\mathrm{Mo}_{x} \mathrm{O}_{y}$-VGCNF materials by X-ray diffraction. This corroborated a crystallite size of Mo oxide species of less than 2-4 nm. Moreover, no bulk $\alpha-\mathrm{MoO}_{3}$ or other molybdenum oxides were detectable by Raman spectroscopy in the asprepared $\mathrm{Mo}_{x} \mathrm{O}_{y}$-VGCNF material.

\subsection{X-ray absorption spectroscopy (XAS)}

In situ transmission XAS experiments were performed at the Mo K edge $(20.0 \mathrm{keV})$ at beamline X1 at the Hamburg Synchrotron Radiation Laboratory, HASYLAB, using a $\mathrm{Si}(311)$ double-crystal monochromator. EXAFS spectra at the Mo K edge in the $k$ space up to $14 \AA^{-1}$ were measured in $\sim 4$ min. For a better time resolution during isothermal experiments at elevated temperatures, Mo $\mathrm{K}$ XANES spectra (19.9-20.3 keV) were measured in $\sim 30 \mathrm{~s}$. For in situ XAFS and catalysis measurements, $23 \mathrm{mg}$ of $\mathrm{Mo}_{x} \mathrm{O}_{y}$-VGCNF were pressed into self-supporting pellets ( $5 \mathrm{~mm}$ in diameter) resulting in an edge jump, $\Delta \mu_{x}$, at the Mo K of about 0.6. Measurements of $\alpha-\mathrm{MoO}_{3}$ and hex$\mathrm{MoO}_{3}$ references have been previously described [9]. Transmission XAS measurements were performed in a suitable in situ cell [19]. Temperature-programmed reduction was conducted in $3 \%$ propene and $\mathrm{He}$ (total flow $30 \mathrm{ml} / \mathrm{min}$ ) in a temperature range from $293 \mathrm{~K}$ to $773 \mathrm{~K}$ at a heating rate of $5 \mathrm{~K} / \mathrm{min}$. Reaction tests were performed in $10 \%$ propene $/ 10 \% \mathrm{O}_{2}$ in $\mathrm{He}$ or $3 \%$ propene $/ 10 \% \mathrm{O}_{2}$ in $\mathrm{He}$ in the temperature range from $293 \mathrm{~K}$ to $723 \mathrm{~K}$ or $293 \mathrm{~K}$ to $673 \mathrm{~K}$, respectively $(5 \mathrm{~K} / \mathrm{min}$, total flow $30 \mathrm{ml} / \mathrm{min}$ ). The gas atmosphere was analyzed using a noncalibrated mass 


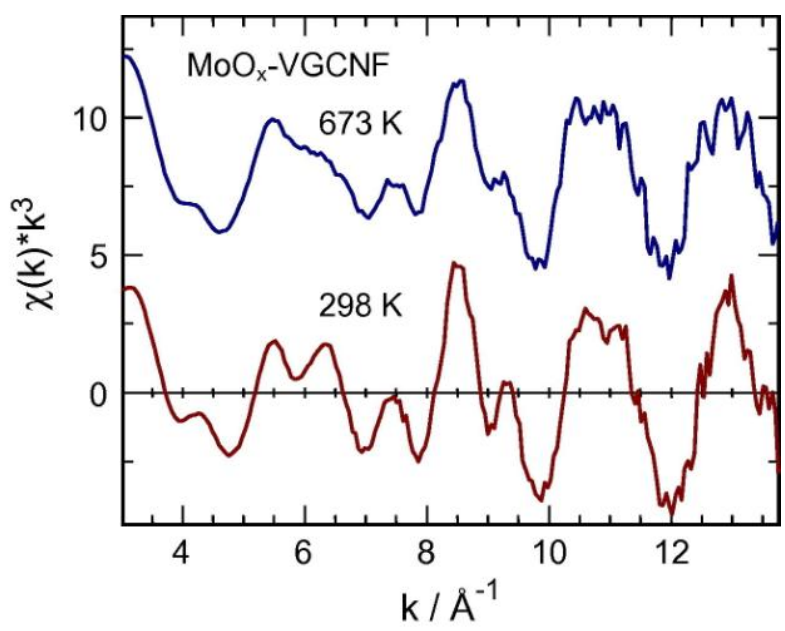

Fig. 1: Mo K edge XAFS $\chi(k) * k^{3}$ of as-prepared and thermally treated $\mathrm{Mo}_{x} \mathrm{O}_{y}$-VGCNF at $298 \mathrm{~K}$ and $673 \mathrm{~K}$, respectively.

spectrometer in a multiple ion detection mode (QMS200 from Pfeiffer).

X-ray absorption fine structure (XAFS) analysis was performed using the software package WinXAS v3.2 [20]. Background subtraction and normalization were carried out by fitting linear polynomials to the pre-edge and 3rd degree polynomials to the post-edge region of an absorption spectrum, respectively. The extended X-ray absorption fine structure (EXAFS) $\chi(k)$ was extracted by using cubic splines to obtain a smooth atomic background $\mu_{0}(k)$. The $\mathrm{FT}\left(\chi(k) * k^{3}\right)$, often referred to as pseudo radial distribution function, was calculated by Fourier transforming the $k^{3}$ weighted experimental $\chi(k)$ function, multiplied by a Bessel window, into the $R$ space. EXAFS data analysis was performed using theoretical backscattering phases and amplitudes calculated with the ab-initio multiple-scattering code FEFF7 [21]. EXAFS refinements were performed in $R$ space simultaneously to magnitude and imaginary part of a Fourier transformed $k^{3}$-weighted and $k^{1}$-weighted experimental $\chi(k)$ using the standard EXAFS formula [22]. This procedure strongly reduces the correlation between the various XAFS fitting parameters. Structural parameters allowed to vary in the refinement were (i) disorder parameter $\sigma^{2}$ of selected single-scattering paths assuming a symmetrical pair-distribution function and (ii) distances of selected single-scattering paths. Coordination numbers $(\mathrm{CN}), E_{0}$ shifts, and amplitude reduction factor $S_{0 \text { were }}^{2}$ kept invariant in the final fitting procedures. Correlations of specific parameters to reduce the number of free running parameters and to improve the stability of the refinement are described below.

The statistical significance of the fitting procedure employed was carefully evaluated in three steps [15]. The procedures used largely correspond to recommendations of the International X-ray Absorption Society on criteria and error reports [23]. First, the number of independent parameters $\left(N_{\text {ind }}\right)$ was calculated according to the Nyquist theorem $N_{\text {ind }}=2 / \pi * \Delta R * \Delta k+2$. In all cases the number of free running parameters in the refinements was well below $N_{\text {ind }}$.
Second, confidence limits were calculated for each individual parameter. In the corresponding procedure, one parameter was successively varied by a certain percentage (i.e. $0.05 \%$ for $R$ and $5 \%$ for $\sigma^{2}$ ) and the refinement was restarted with this parameter kept invariant. The parameter was repeatedly increased or decreased until the fit residual exceed the original fit residual by more than $5 \%$. Eventually, the confidence limit of the parameter was obtained from linear interpolation between the last and second last increment for an increase in fit residual of $5 \%$. This procedure was consecutively performed for each fitting parameter. Third, a so-called $F$ test was performed to assess the significance of the effect of additional fitting parameters on the fit residual [24]. Fit parameters employed exhibited $F$ values below 0.2 and are statistically significant.

\subsection{Quantitative catalysis measurements}

Quantitative catalysis measurements were performed in the laboratory using the XAS in situ cell connected to an online gas chromatography system (Varian CP-3800) and a noncalibrated mass spectrometer (Pfeiffer QMS). Hydrocarbons and oxygenated reaction products were analyzed using a Carbowax 52CB capillary column connected to a $\mathrm{Al}_{2} \mathrm{O}_{3} / \mathrm{MAPD}$ capillary column or a fused silica restriction $(25 \mathrm{~m} \times 0.32 \mathrm{~mm})$ each connected to a flame ionization detector (FID). Reactant gas flow rates of oxygen, propene, and Helium were adjusted through separate mass flow controllers to a total flow of $40 \mathrm{ml} / \mathrm{min}$. A mixture of $5 \%$ propene and 5\% oxygen in helium was used for catalytic tests in the range of 295-748 K. Sample mass, BN diluent, and pellet preparation were the same as for the XAFS studies.

\section{Results and discussion}

\subsection{Local structure of as-prepared Mo oxide species on VGCNF}

The EXAFS $\chi(k)$ of as-prepared and thermally treated $\mathrm{Mo}_{x} \mathrm{O}_{y}$-VGCNF are depicted in Fig. 1. Apparently, the data quality obtained permits reliable data analysis up to $\sim 14 \AA^{-1}$ even under reaction conditions at temperatures above $623 \mathrm{~K}$. The XANES spectrum of $\mathrm{Mo}_{x} \mathrm{O}_{y}-\mathrm{VGCNF}$ is shown together with those of hexagonal $\mathrm{MoO}_{3}$ and $\alpha-\mathrm{MoO}_{3}$ in Fig. 2. The structural relationship between these two modifications will be discussed below. Comparison with the spectra of those references indicates a local structure around the Mo centers in $\mathrm{Mo}_{x} \mathrm{O}_{y}$-VGCNF related to that in bulk molybdenum trioxides. Magnitude and imaginary part of the $\mathrm{FT}\left(\chi(k) * k^{3}\right)$ of $\mathrm{Mo}_{x} \mathrm{O}_{y}$-VGCNF are compared to that of hex- $-\mathrm{MoO}_{3}$ and $\alpha-\mathrm{MoO}_{3}$ in Fig. 3. Shape and peak positions of the $\mathrm{FT}\left(\chi(k) * k^{3}\right)$ of $\mathrm{Mo}_{x} \mathrm{O}_{y}$-VGCNF appear to be more similar to that of the hexagonal modification of $\mathrm{MoO}_{3}$ (Fig. 3a). A good agreement in the ranges from 1 to $2 \AA$ and 4 to $6 \AA$ can be seen. Between 2 and $4 \AA$, the amplitude 


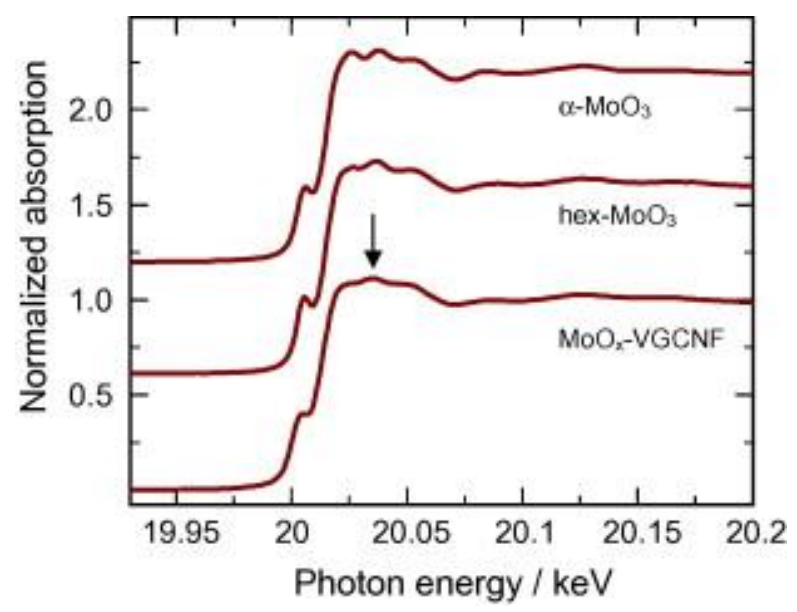

Fig. 2: Mo K edge XANES spectra of $\mathrm{Mo}_{x} \mathrm{O}_{y}-\mathrm{VGCNF}$ compared to the spectra of references $\alpha-\mathrm{MoO}_{3}$ and hex- $\mathrm{MoO}_{3}$ (arrow indicates features used for calculating average valence).
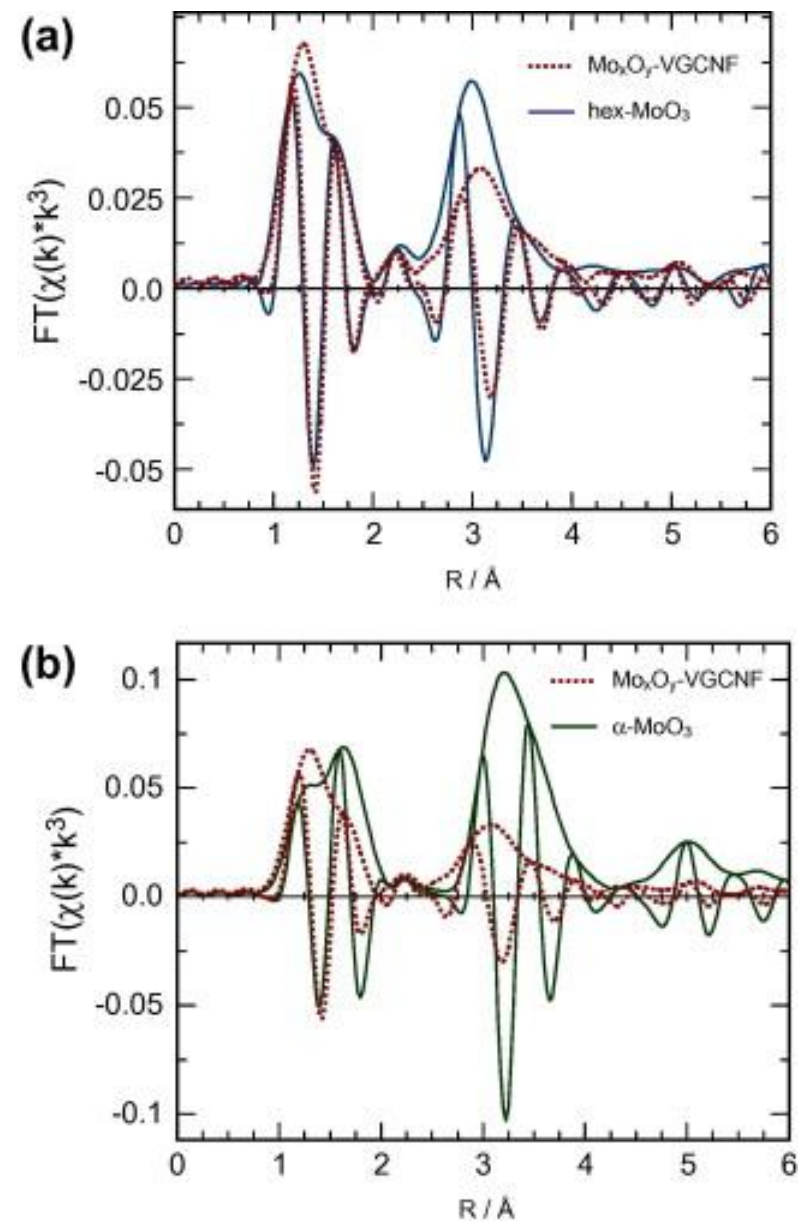

Fig. 3: Magnitude and imaginary part of $\mathrm{FT}\left(\chi(k) * k^{3}\right)$ of $\mathrm{Mo}_{x} \mathrm{O}_{y^{-}}$ VGCNF compared to that of reference hex- $-\mathrm{MoO}_{3}$ (a) and $\alpha-\mathrm{MoO}_{3}$ (b).

of $\mathrm{Mo}_{x} \mathrm{O}_{y}-\mathrm{VGCNF}$ is reduced compared to hex- $\mathrm{MoO}_{3}$. Apparently, hex- $\mathrm{MoO}_{3}$ is a suitable model system to simulate the experimental spectra of $\mathrm{Mo}_{x} \mathrm{O}_{y}$-VGCNF. Hence, a theoretical XAFS function calculated for a hex $-\mathrm{MoO}_{3}$ mod- el structure was refined to the $\mathrm{FT}\left(\chi(k) * k^{3}\right)$ of as-prepared $\mathrm{Mo}_{x} \mathrm{O}_{y}$-VGCNF. Additionally, the same procedure was applied to simulate the $\mathrm{FT}\left(\chi(k) * k^{3}\right)$ of crystalline bulk references hex- $-\mathrm{MoO}_{3}$ and $\alpha-\mathrm{MoO}_{3}$. The resulting theoretical and experimental $\mathrm{FT}\left(\chi(k) * k^{3}\right)$ as-prepared $\mathrm{Mo}_{x} \mathrm{O}_{y^{-}}$ VGCNF are depicted in Fig. 4. The corresponding fitting parameters are given in Table 1.

The fitting procedure chosen was equally well suited to simulate the experimental $\mathrm{FT}\left(\chi(k) * k^{3}\right)$ of both asprepared $\mathrm{Mo}_{x} \mathrm{O}_{y}$-VGCNF and references hex- $\mathrm{MoO}_{3}$ and $\alpha$ $\mathrm{MoO}_{3}$ (Table 1). The good agreement between theoretical and experimental $\mathrm{FT}\left(\chi(k) * k^{3}\right)$ of $\mathrm{Mo}_{x} \mathrm{O}_{y}$-VGCNF (Fig. 4) confirmed that the local structure of the Mo oxide species supported on VGCNF can be well described by that of hexagonal $\mathrm{MoO}_{3}$. Characteristic Mo-O and Mo-Mo paths in the local structure of hex- $\mathrm{MoO}_{3}$ and the corresponding single-scattering $\mathrm{FT}\left(\chi(k) * k^{3}\right)$ are also shown in Fig. 4. The Mo-Mo distances required to describe the experimental $\mathrm{FT}\left(\chi(k) * k^{3}\right)$ of $\mathrm{Mo}_{x} \mathrm{O}_{y}-\mathrm{VGCNF}$ and the reference materials include one in-plane distance of corner-sharing $\mathrm{MoO}_{6}$ units and two distances of corner-sharing and edge-sharing $\mathrm{MoO}_{6}$ units perpendicular to the basal plane of hex- $\mathrm{MoO}_{3}$. This structural arrangement indicates a three-dimensional $\mathrm{MoO}_{3}$ structure supported on VGCNF. Given the $k$ range used for EXAFS refinement, the spatial resolution according to $d R=\pi / 2 k_{\max }$ with $k_{\max }=14 \AA^{-1}$ amounted to $d R=0.11 \AA$. Therefore, and in addition to the results of the statistical evaluation, distances and $\sigma^{2}$ parameters of the first two Mo-O pairs (i.e. $1.69 \AA$ and $1.75 \AA ; 1.97 \AA$ and $2.21 \AA$ ) were refined the same (i.e. the corresponding differences $\Delta R$ with respect to the hex $-\mathrm{MoO}_{3}$ model structure were refined the same).

The reference hex- $\mathrm{MoO}_{3}$ measured corresponds to a mechanical mixture of bulk hex- $\mathrm{MoO}_{3}$ and VGCNF in a similar ratio as the $\mathrm{Mo}_{x} \mathrm{O}_{y}$-VGCNF material (Fig. 2). The XANES and EXAFS spectra of this reference are similar to those of bulk hex- $\mathrm{MoO}_{3}$. Conversely, the amplitude of the XANES features of $\mathrm{Mo}_{x} \mathrm{O}_{y}$-VGCNF appeared to be reduced compared to the reference oxides. Moreover, the $\mathrm{FT}\left(\chi(k) * k^{3}\right)$ of $\mathrm{Mo}_{x} \mathrm{O}_{y}$-VGCNF also exhibited a slightly reduced amplitude for the higher Mo-Mo shells (Fig. 3). This reduced amplitude may be caused by the small size of the oxide particles (reduced average $\mathrm{CN}$ ) or static disorder in the particles (broadened distance distribution increases $\sigma^{2}$ ). In principal, XAFS data analysis should be able to distinguish both effects by simultaneously refining $\mathrm{CN}$ and $\sigma^{2}$ in the corresponding fitting procedure. However, evaluating the correlation between these parameters revealed that this was not feasible. Fitting results of an EXAFS refinement procedure using free coordination numbers and $\sigma^{2}$ parameters to simulate the experimental $\mathrm{FT}\left(\chi(k) * k^{3}\right)$ of reference hexagonal $\mathrm{MoO}_{3}$ are given in Table 2. While Mo-O and Mo-Mo distances are in good agreement with the crystallographic structure of hex $-\mathrm{MoO}_{3}$ (Table 1), coordination numbers $\mathrm{CN}$ considerably exceed the crystallographic values. The corresponding $\sigma^{2}$ parameters are also increased compared to the parameters given in Table 1 to account for the increased amplitude. Moreover, calculations 
Table 1: Type and number $(N)$ of atoms at distance $R$ from the absorbing Mo atom in the local structure of $\alpha-\mathrm{MoO}_{3}$, hex-MoO $\mathrm{M}_{3}$, and as-prepared $\mathrm{Mo}_{x} \mathrm{O}_{y}$-VGCNF. Experimental distances and XAFS disorder parameters $\left(\sigma^{2}\right)$ were obtained from the refinement of a hex-MoO $\mathrm{M}_{3}$ model structure to the experimental Mo K edge XAFS FT $\left(\chi(k) * k^{3}\right.$ ) of $\alpha-\mathrm{MoO}_{3}$ (residual 9.0), hex- $\mathrm{MoO}_{3}$ (residual 9.7), and as-prepared $\mathrm{Mo}_{x} \mathrm{O}_{y}-\mathrm{VGCNF}$ (residual 7.8) (Fig. 4) ( $k$ range from 3.0 to $14.0 \AA^{-1}, R$ range $0.9-4.0 \AA, N_{\text {ind }}=24, E_{0}=0 \mathrm{eV}, N_{\text {free }}=11$ ). Subscript C indicates parameters that were correlated in the refinement (same $\Delta R$ with respect to model structure or $\sigma^{2}$ ). Confidence limits of refined parameters are included.

\begin{tabular}{|c|c|c|c|c|c|c|c|c|c|}
\hline \multirow[t]{2}{*}{ Type } & \multirow[t]{2}{*}{$N$} & \multicolumn{3}{|c|}{$\alpha-\mathrm{MoO}_{3}$} & \multicolumn{3}{|c|}{$\mathrm{Hex}-\mathrm{MoO}_{3}$} & \multicolumn{2}{|c|}{ As-prep $\mathrm{Mo}_{x} \mathrm{O}_{y}$-VGCNF } \\
\hline & & $R_{\mathrm{T}}(\AA)$ & $R_{\mathbb{E}}(\AA)$ & $\sigma^{2}\left(\AA^{2}\right)$ & $R_{\mathrm{T}}(\AA)$ & $R_{\mathbb{E}}(\AA)$ & $\sigma^{2}\left(\AA^{2}\right)$ & $R(\AA)$ & $\sigma^{2}\left(\AA^{2}\right)$ \\
\hline Mo-O & 1 & 1.67 & 1.69 & 0.0025 & 1.68 & 1.69 & 0.0014 & $1.69 \pm 0.008$ & $0.0008 \pm 0.0001$ \\
\hline Mo-O & 1 & 1.73 & $1.75 c$ & $0.0025 c$ & 1.73 & $1.75 \mathrm{c}$ & $0.0014 c$ & $1.75 c$ & $0.0008_{c}$ \\
\hline Mo-O & 2 & 1.95 & 1.97 & 0.0012 & 1.97 & 1.97 & 0.0036 & $1.97 \pm 0.006$ & $0.0041 \pm 0.0003$ \\
\hline Mo-O & 1 & 2.25 & $2.21_{\mathrm{c}}$ & $0.0012_{c}$ & 2.21 & $2.21_{\mathrm{c}}$ & $0.0036_{c}$ & $2.21_{c}$ & $0.0041_{C}$ \\
\hline Mo-O & 1 & 2.33 & 2.35 & 0.0017 & 2.39 & 2.39 & 0.0016 & $2.40 \pm 0.008$ & $0.0028 \pm 0.001$ \\
\hline Mo-Mo & 2 & 3.44 & 3.44 & 0.0025 & 3.31 & 3.36 & 0.0035 & $3.37 \pm 0.004$ & $0.0068 \pm 0.0003$ \\
\hline Mo-Mo & 2 & 3.70 & 3.75 & $0.0025 c$ & 3.73 & 3.76 & $0.0035 c$ & $3.79 \pm 0.007$ & $0.0068_{c}$ \\
\hline Mo-Mo & 2 & 3.97 & 4.07 & 0.004 & 4.03 & 3.95 & 0.0089 & $4.03 \pm 0.01$ & $0.0109 \pm 0.003$ \\
\hline
\end{tabular}
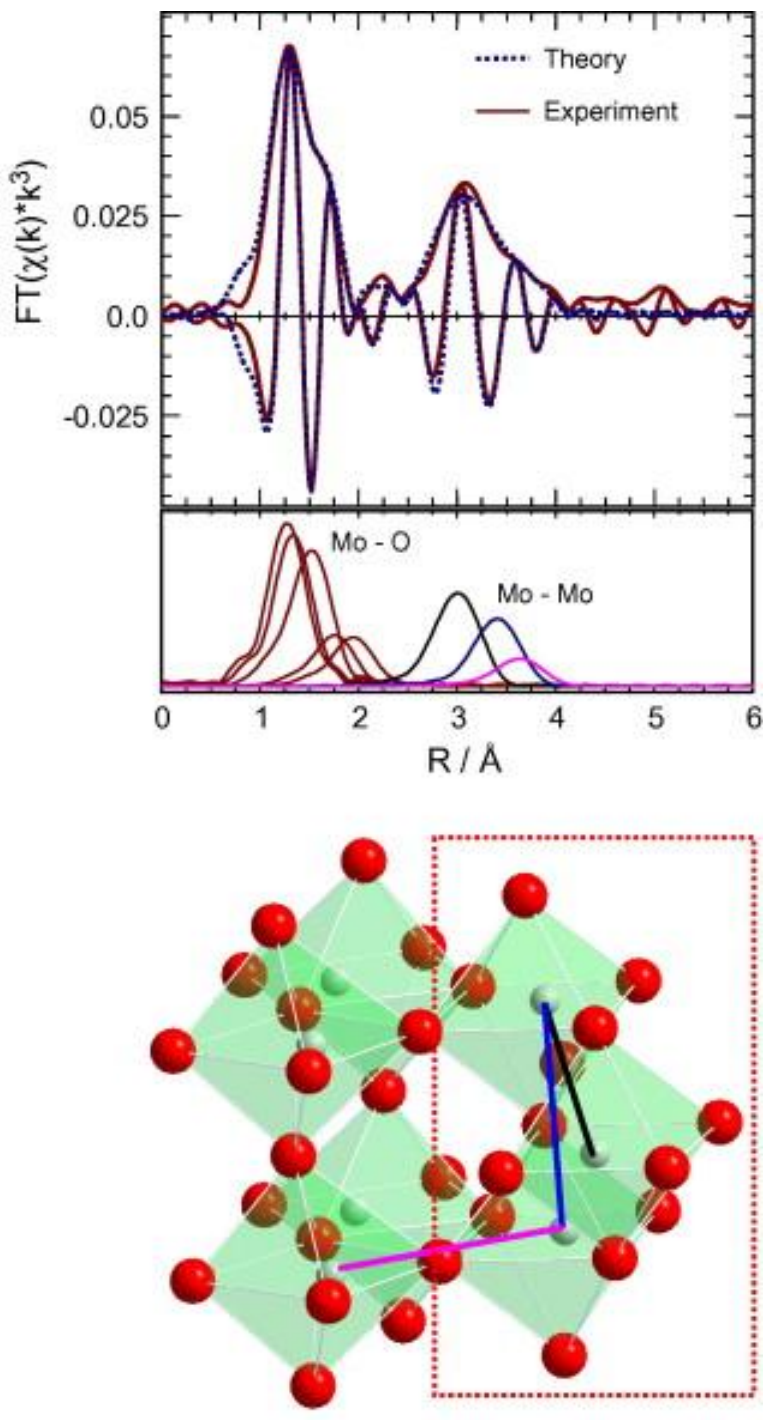

Fig. 4: Experimental (solid) Mo $\mathrm{K}$ edge $\mathrm{FT}\left(\chi(k) * k^{3}\right)$ of $\mathrm{Mo}_{x} \mathrm{O}_{y^{-}}$ VGCNF together with a theoretical XAFS function (fitting results are given in Table 1). $\mathrm{FT}\left(\chi(k) * k^{3}\right)$ of the individual Mo-O and Mo-Mo scattering paths and a schematic representation of the local structure of hex- $\mathrm{MoO}_{3}$ (dotted rectangle emphasizes building unit of hex- $-\mathrm{MoO}_{3}$ and $\alpha-\mathrm{MoO}_{3}$ ). of confidence intervals resulted in very large values for the Mo-Mo coordination numbers. Hence, in particular, CN and $\sigma^{2}$ parameters were strongly correlated, and corresponding fitting procedures with independent $\mathrm{CN}$ and $\sigma^{2}$ resulted in very large uncertainties.

Apparently, EXAFS fitting procedures with independent $\mathrm{CN}$ and $\sigma^{2}$ are not even suited to simulate the $\mathrm{FT}\left(\chi(k) * k^{3}\right)$ of an ideal reference $\mathrm{MoO}_{3}$. Thus, two approaches were attempted to keep either $\mathrm{CN}$ or $\sigma^{2}$ invariant in the refinements. First, varying $\mathrm{CN}$ and fixing $\sigma^{2}$ to values determined for crystalline bulk references and, second, fixing $\mathrm{CN}$ to bulk values and varying $\sigma^{2}$. It was found that the second approach yielded the lowest fit residual (7.8) compared to the first approach (9.9). Hence, we decided to account for the reduced amplitude by refining only the disorder parameter $\sigma^{2}$. A physical interpretation of $\sigma^{2}$ in terms of particle sizes, however, is hardly possible. Eventually, we may speculate that static disorder in the supported Mo oxide phase contributed more to the reduced amplitude of the $\mathrm{FT}\left(\chi(k) * k^{3}\right)$ of $\mathrm{Mo}_{x} \mathrm{O}_{y}$-VGCNF than the average coordination number in the small particles. In conclusion, we suggest that the reduced FT amplitudes correspond to small disordered particles or reduced extension of the hexagonal $\mathrm{MoO}_{3}$ structure on the VGCNF support. This agrees with previous electron microscopy and Raman studies which showed no detectable amount of bulk $\mathrm{MoO}_{3}$ phases. Apparently, the carbon nanofibers support a dispersed molybdenum oxide species with a local structure similar to that of hex- $\mathrm{MoO}_{3}$.

$\alpha-\mathrm{MoO}_{3}$ and hexagonal $\mathrm{MoO}_{3}$ exhibit a distinct structural relationship that is readily visible in the very similar XANES spectra, $\mathrm{FT}\left(\chi(k) * k^{3}\right)$, and structural parameters given in Table 1. A similar spectroscopic fingerprint of the two references is caused by the same building block consisting of three edge and corner-sharing $\mathrm{MoO}_{6}$ units (Fig. 4). The structural relationship is also visible in the schematic representation of $\alpha-\mathrm{MoO}_{3}$ and hexagonal $\mathrm{MoO}_{3}$ depicted in Fig. 5. The similarity between the two structures suggests an easy and rapid transformation from hexagonal $\mathrm{MoO}_{3}$ to orthorhombic $\alpha-\mathrm{MoO}_{3}$. Mo-O and Mo-Mo distances around the Mo absorber in $\alpha-\mathrm{MoO}_{3}$ and hex$\mathrm{MoO}_{3}$ are given in Table 1. Despite their different longrange order structures, the local structure around the Mo 


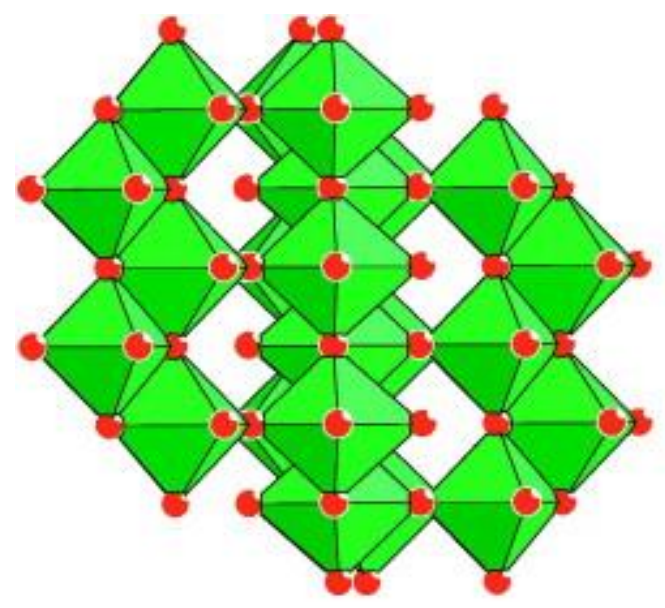

hexagonal $\mathrm{MoO}_{3}$

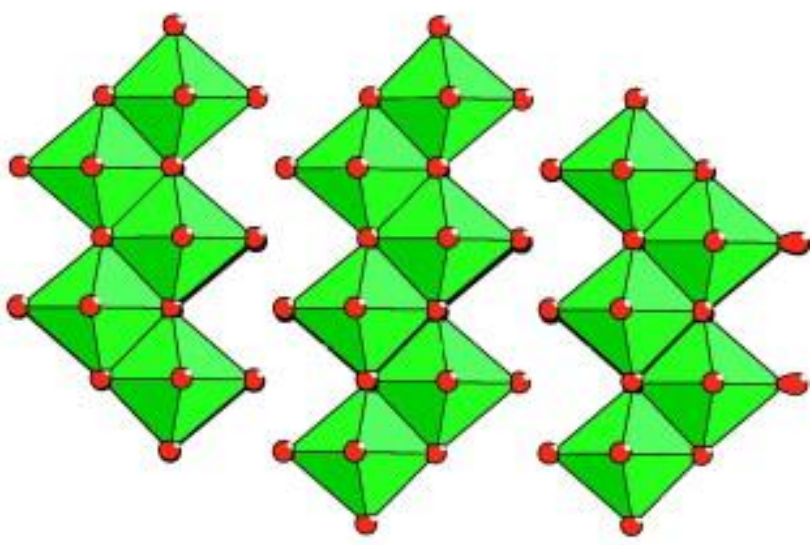

$\alpha-\mathrm{MoO}_{3}$

Fig. 5: Schematic representation of the structure of hex- $\mathrm{MoO}_{3}$ and $\alpha-\mathrm{MoO}_{3}$. The orientation was chosen to emphasize the structural relationship.

Table 2: Type and number $(N)$ of atoms at distance $R$ from the absorbing Mo atom in the local structure of hex- $\mathrm{MoO}_{3}$. Experimental coordination numbers, distances, and XAFS disorder parameters $\left(\sigma^{2}\right)$ were obtained from the refinement of a hex- $\mathrm{MoO}_{3}$ model structure to the experimental Mo $\mathrm{K}$ edge XAFS $\mathrm{FT}\left(\chi(k) * \mathrm{k}^{3}\right)$ of hex $-\mathrm{MoO}_{3}$ ( $k$ range from 3.0 to $14.0 \AA^{-1}, R$ range $0.9-4.0 \AA, N_{\text {ind }}=24, E_{0}=0 \mathrm{eV}$, fit residual 8.5, $\left.N_{\text {free }}=14\right)$. Subscript $\mathrm{C}$ indicates parameters that were correlated in the refinement (same $\Delta R$ with respect to model structure or $\sigma^{2}$ ). Confidence limits of refined parameters are included.

\begin{tabular}{|c|c|c|c|c|c|}
\hline \multirow[t]{2}{*}{ Type } & \multicolumn{2}{|c|}{ Model hex $-\mathrm{MoO}_{3}$} & \multicolumn{3}{|c|}{ Experimental reference hex $-\mathrm{MoO}_{3}$} \\
\hline & $N$ & $R(\AA)$ & $N$ & R & $\sigma^{2}$ \\
\hline Mo-O & 1 & 1.68 & 1 & $1.69 \pm 0.002$ & $0.0012 \pm 0.0002$ \\
\hline Mo-O & 1 & 1.73 & 1 & $1.75 c$ & $0.0012 c$ \\
\hline Mo-O & 2 & 1.97 & 2 & $1.97 \pm 0.005$ & $0.0036 \pm 0.0004$ \\
\hline Mo-O & 1 & 2.21 & 1 & $2.21_{\mathrm{c}}$ & $0.0036 c$ \\
\hline Mo-O & 1 & 2.39 & 1 & $2.39 \pm 0.02$ & $0.0031 \pm 0.002$ \\
\hline Mo-Mo & 2 & 3.31 & $4.6 \pm 3.8$ & $3.37 \pm 0.007$ & $0.0084 \pm 0.0002$ \\
\hline Mo-Mo & 2 & 3.73 & $3.2 \pm 1.9$ & $3.81 \pm 0.008$ & $0.0084_{c}$ \\
\hline Mo-Mo & 2 & 4.03 & $2.5 \pm 3.0$ & $4.02 \pm 0.05$ & $0.0081 \pm 0.001$ \\
\hline
\end{tabular}

centers in $\alpha-\mathrm{MoO}_{3}$ and hex- $-\mathrm{MoO}_{3}$ is very similar. While the building blocks of $\alpha-\mathrm{MoO}_{3}$ and hex- $\mathrm{MoO}_{3}$ possess the same coordination numbers, minor deviations exist in characteristic Mo-O distances (e.g. $2.35 \AA\left[\alpha-\mathrm{MoO}_{3}\right]$ and $2.39 \AA\left[\right.$ hex- $\left.-\mathrm{MoO}_{3}\right]$ ) and Mo-Mo distances (e.g. 3.44 and $4.07 \AA\left[\alpha-\mathrm{MoO}_{3}\right]$ and 3.36 and $3.95 \AA$ [hex- $\left.\left.-\mathrm{MoO}_{3}\right]\right)$. With respect to the corresponding confidence limits given in Table 1, it appears that the fitting procedure employed permits distinguishing the local structure of $\alpha-\mathrm{MoO}_{3}$ and hex- $\mathrm{MoO}_{3}$.

During decomposition of ammonium heptamolybdate, hex- $\mathrm{MoO}_{3}$ is formed as an intermediate which rapidly transforms into $\alpha-\mathrm{MoO}_{3}$ at temperatures above $623 \mathrm{~K}$ [25]. The latter is accompanied by the evolution of ammonia or water from the channels of hex- $\mathrm{MoO}_{3}$. Sufficiently strong support-metal oxide interaction can stabilize the channel structure of hex- $\mathrm{MoO}_{3}$ even at temperatures up to $773 \mathrm{~K}$ and prevent transformation to $\alpha-\mathrm{MoO}_{3}$. This was recently shown for hex- $\mathrm{MoO}_{3}$ supported on $\mathrm{SiO}_{2}(\mathrm{SBA}-15)$ [9]. The $\mathrm{Mo}_{x} \mathrm{O}_{y}$-VGCNF sample was calcined at $623 \mathrm{~K}$, which may explain the presence of hex- $\mathrm{MoO}_{3}$ as major phase supported on VGCNF. The strength of the interaction between Mo oxide and VGCNF in $\mathrm{Mo}_{x} \mathrm{O}_{y}$-VGCNF was further investigated by temperature-programmed reduction and reaction in propene and propene/oxygen, respectively.

\subsection{Reactivity of as-prepared Mo oxide species on VGCNF}

Evolution of Mo K edge XANES spectra of $\mathrm{Mo}_{x} \mathrm{O}_{y^{-}}$ VGCNF during temperature-programmed reduction in $3 \%$ propene in the temperature range from $300 \mathrm{~K}$ to $773 \mathrm{~K}$ is depicted in Fig. 6. A characteristic change in the near-edge structure can be seen at $\sim 623 \mathrm{~K}$ that corresponds to the reduction of $\mathrm{MoO}_{3}$ to $\mathrm{MoO}_{2}$. Similar to bulk hex- $\mathrm{MoO}_{3}$ or $\alpha-\mathrm{MoO}_{3}, \mathrm{Mo}_{x} \mathrm{O}_{y}-\mathrm{VGCNF}$ is readily reduced in a propene atmosphere at elevated temperatures. This is in contrast to hex- $\mathrm{MoO}_{3}$ stabilized on SBA-15, which showed no deep reduction and formation of $\mathrm{MoO}_{2}$ even at $773 \mathrm{~K}$ in propene [9]. Compared to SBA-15, the metal oxide-support interaction in $\mathrm{Mo}_{x} \mathrm{O}_{y}$-VGCNF appears to be weaker and not sufficient to stabilize hex- $\mathrm{MoO}_{3}$ at high temperatures.

Temperature-programmed reaction studies were first conducted in $10 \%$ propene and $10 \%$ oxygen in He. Evolution of Mo K edge XANES spectra and $\operatorname{FT}\left(\chi(k) * k^{3}\right)$ of $\mathrm{Mo}_{x} \mathrm{O}_{y}$-VGCNF in the temperature range from $300 \mathrm{~K}$ to $723 \mathrm{~K}$ is depicted in Fig. 7. Interestingly, $\mathrm{Mo}_{x} \mathrm{O}_{y}$-VGCNF exhibited a reduction to $\mathrm{MoO}_{2}$ at $\sim 723 \mathrm{~K}$. Upon cooling to $623 \mathrm{~K}$ in propene and oxygen, the material was re-oxidized to $\alpha-\mathrm{MoO}_{3}$. Neither $\alpha-\mathrm{MoO}_{3}$ nor bulk hex-MoO 3 showed a similar intermediate reduction in our previous investigations. Apparently, interaction with the VGCNF results in a highly reactive $\mathrm{MoO}_{3}$, which despite the presence of oxygen in the gas phase is temporarily reduced in an equal 


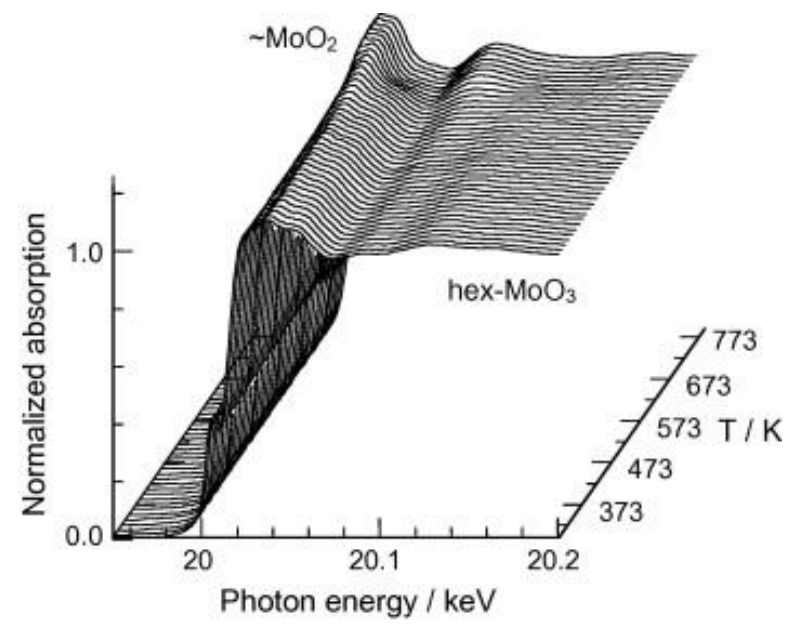

Fig. 6: Evolution of Mo $\mathrm{K}$ edge XANES spectra of $\mathrm{Mo}_{x} \mathrm{O}_{y^{-}}$ VGCNF measured during temperature-programmed reduction in $3 \%$ propene in $\mathrm{He}\left(298-773 \mathrm{~K}, 4 \mathrm{~K} / \mathrm{min}\right.$, major $\mathrm{MoO}_{x}$ species on VGCNF are indicated).
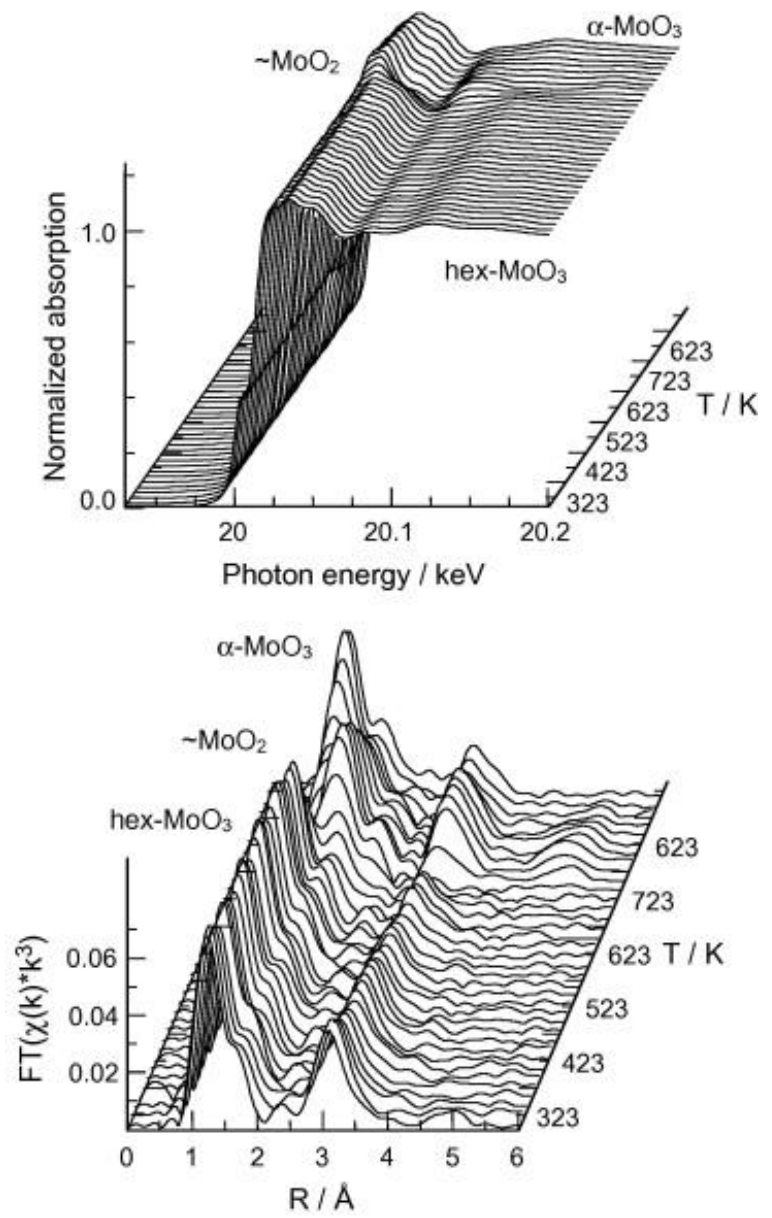

Fig. 7: Evolution of Mo K edge XANES spectra and $\mathrm{FT}\left(\chi(k) * k^{3}\right)$ of $\mathrm{Mo}_{x} \mathrm{O}_{y}$-VGCNF measured during thermal treatment in $3 \%$ propene/10\% oxygen in $\mathrm{He}(298-673 \mathrm{~K}, 5 \mathrm{~K} / \mathrm{min}$, hold at $673 \mathrm{~K}$, major $\mathrm{MoO}_{x}$ species on VGCNF are indicated). mixture of propene and oxygen. In order to avoid reduction of $\mathrm{Mo}_{x} \mathrm{O}_{y}$-VGCNF in propene/oxygen, the concentration of propene in the gas phase and the reaction temperature were lowered. Subsequent reaction experiments were performed in $3 \%$ propene and $10 \%$ oxygen at temperatures up to $673 \mathrm{~K}$.

Evolution of Mo $\mathrm{K}$ edge XANES spectra and $\mathrm{FT}\left(\chi(k) * k^{3}\right)$ of $\mathrm{Mo}_{x} \mathrm{O}_{y}$-VGCNF during thermal treatment in $3 \%$ propene and $10 \%$ oxygen in the temperature range from $300 \mathrm{~K}$ to $673 \mathrm{~K}$ is depicted in Fig. 8. Here, no intermediate reduction and formation of $\mathrm{MoO}_{2}$ are observed in the XANES and EXAFS spectra. However, minor changes in the spectra can be seen at temperatures above $623 \mathrm{~K}$ indicative of a structural transformation of $\mathrm{Mo}_{x} \mathrm{O}_{y}$-VGCNF under reaction conditions. The $\mathrm{FT}\left(\chi(k) * k^{3}\right)$ of activated $\mathrm{Mo}_{x} \mathrm{O}_{y}$-VGCNF is compared to that of $\alpha-\mathrm{MoO}_{3}$ at $673 \mathrm{~K}$ in Fig. 9. While differences can be observed in the amplitude of the magnitude of the $\mathrm{FT}\left(\chi(k) * k^{3}\right)$, the imaginary part exhibits a very similar oscillatory behavior. Apparently, starting from a hexagonal $\mathrm{MoO}_{3}$ in the as-prepared material the local structure of activated $\mathrm{Mo}_{x} \mathrm{O}_{y}$-VGCNF became more similar to that of $\alpha-\mathrm{MoO}_{3}$ during thermal treatment.
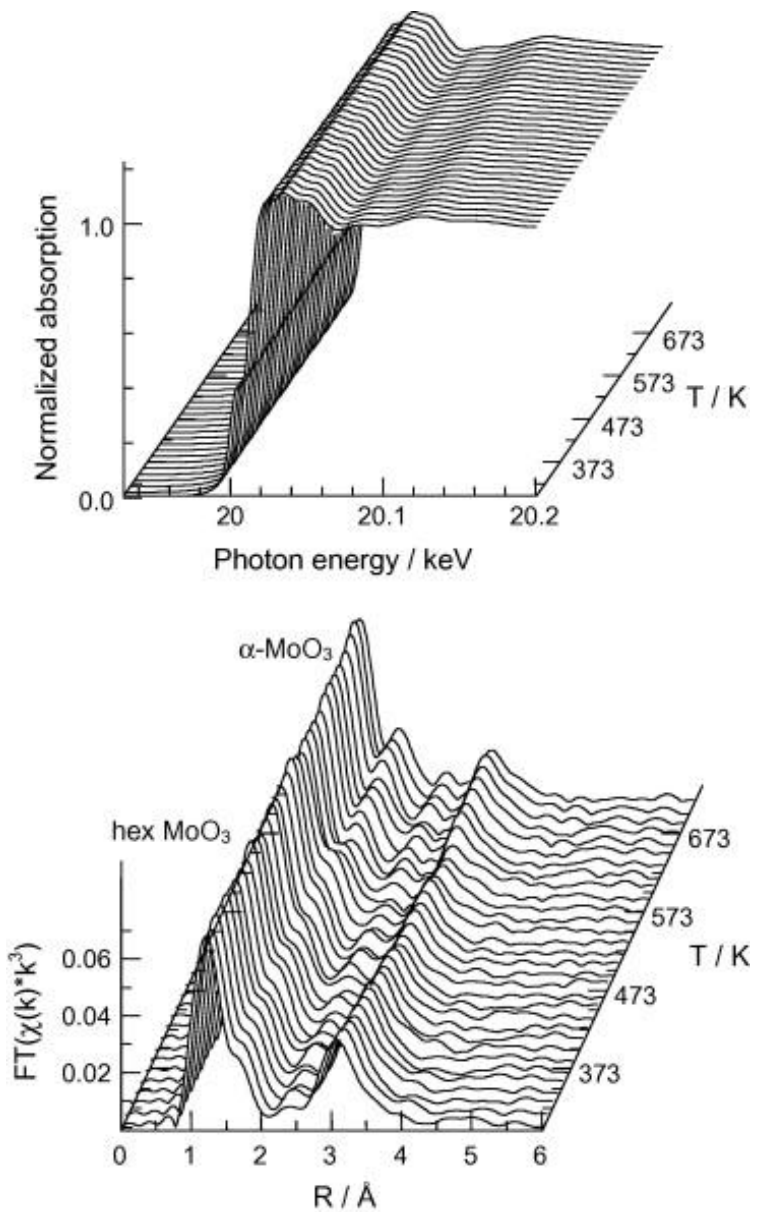

Fig. 8: Evolution of Mo K edge XANES spectra and $\operatorname{FT}\left(\chi(k) * k^{3}\right)$ of $\mathrm{Mo}_{x} \mathrm{O}_{y}$-VGCNF measured during thermal treatment in $3 \%$ propene/10\% oxygen in $\mathrm{He}(298-673 \mathrm{~K}, 5 \mathrm{~K} / \mathrm{min}$, hold at $673 \mathrm{~K}$, major $\mathrm{MoO}_{x}$ species on VGCNF are indicated). 


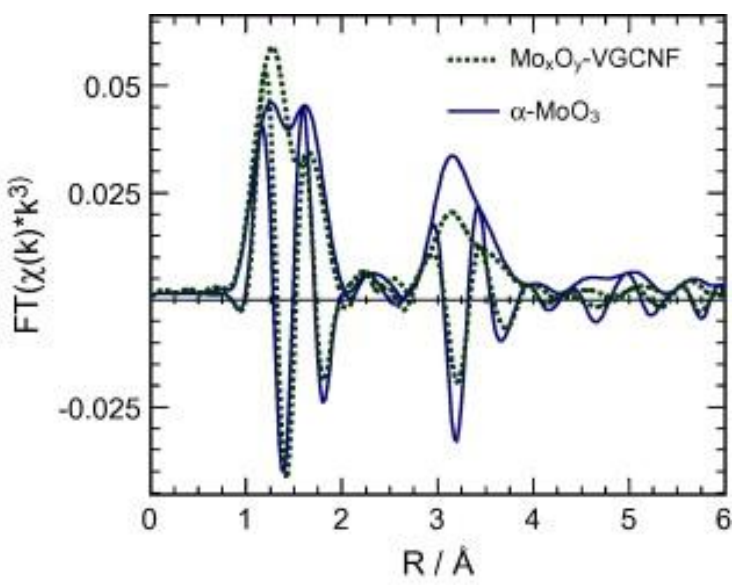

Fig. 9: Comparison of Mo $\mathrm{K}$ edge $\mathrm{FT}\left(\chi(k) * k^{3}\right)$ of "activated" $\mathrm{Mo}_{x} \mathrm{O}_{y}-\mathrm{VGCNF}$ (dashed) (Fig. 8) and $\alpha-\mathrm{MoO}_{3}$ (solid) at $673 \mathrm{~K}$.

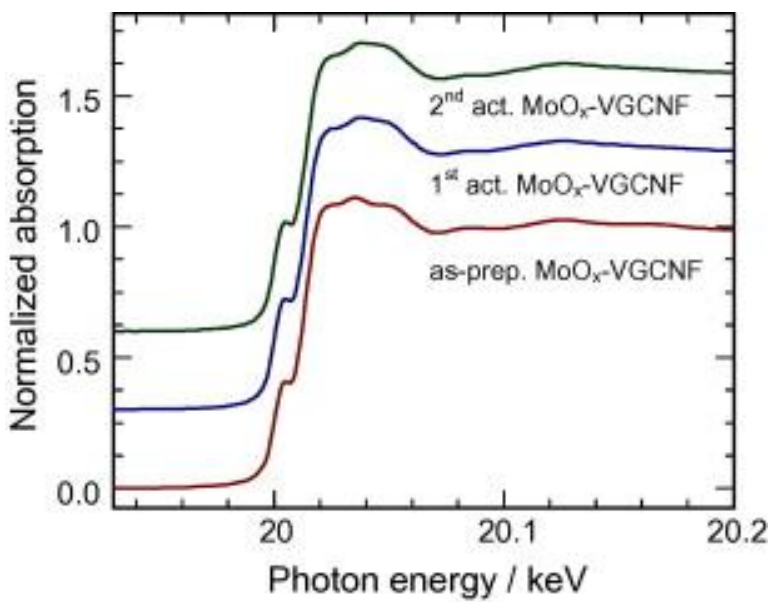

Fig. 10: Mo K edge XANES spectra of as-prepared and activated $\mathrm{Mo}_{x} \mathrm{O}_{y}$-VGCNF. Both "activated" samples were measured in 3\% propene $/ 10 \%$ oxygen at $673 \mathrm{~K}$. "2nd act" corresponds to a $\mathrm{Mo}_{x} \mathrm{O}_{y}$ VGCNF sample that was previously further reduced by treatment in $3 \%$ propene at $723 \mathrm{~K}$.

Somewhat in contrast to the similar $\operatorname{FT}\left(\chi(k) * k^{3}\right)$ of $\alpha-\mathrm{MoO}_{3}$ and activated $\mathrm{Mo}_{x} \mathrm{O}_{y}$-VGCNF (Fig. 9), a significantly different shape of the XANES spectrum of activated $\mathrm{Mo}_{x} \mathrm{O}_{y}$-VGCNF compared to as-prepared $\mathrm{Mo}_{x} \mathrm{O}_{y}$-VGCNF (Fig. 2) and $\alpha-\mathrm{MoO}_{3}$ was observed (Fig. 10). This indicates a different medium-range order and electronic structure of activated $\mathrm{Mo}_{x} \mathrm{O}_{y}$-VGCNF compared to $\alpha-\mathrm{MoO}_{3}$ and hex$\mathrm{MoO}_{3}$. Moreover, reduction ( $723 \mathrm{~K}$ in $3 \%$ propene) and reoxidation ( $673 \mathrm{~K}$ in $3 \%$ propene and $10 \%$ oxygen) of activated $\mathrm{Mo}_{x} \mathrm{O}_{y}$-VGCNF resulted in the formation of the same characteristic XANES spectrum. Apparently, the characteristic local structure of activated $\mathrm{Mo}_{x} \mathrm{O}_{y}$-VGCNF exhibited a reversible reduction and re-oxidation behavior and a pronounced stability.

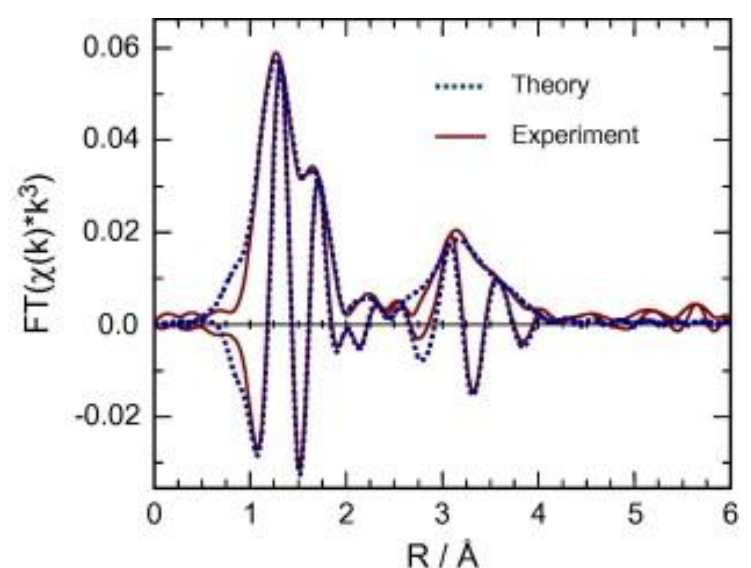

Fig. 11: Experimental (solid) Mo $\mathrm{K}$ edge $\mathrm{FT}\left(\chi(k) * k^{3}\right)$ of $\mathrm{Mo}_{x} \mathrm{O}_{y^{-}}$ VGCNF measured in situ during thermal treatment in $3 \%$ propene $10 \%$ oxygen at $673 \mathrm{~K}$ together with a theoretical XAFS function (fitting results are given in Table 3 ).

\subsection{Local structure of activated MoxOy-VGCNF}

In order to elucidate the local structure of $\mathrm{Mo}_{x} \mathrm{O}_{y}$-VGCNF at temperatures above $623 \mathrm{~K}$ in propene and oxygen (i.e. activated $\mathrm{Mo}_{x} \mathrm{O}_{y}$-VGCNF), a detailed EXAFS analysis was performed. Again, the hexagonal $\mathrm{MoO}_{3}$ model structure was chosen as starting point, and the same refinement procedure as described above was employed. Experimental and theoretical $\mathrm{FT}\left(\chi(k) * k^{3}\right)$ of activated $\mathrm{Mo}_{x} \mathrm{O}_{y}$-VGCNF are shown in Fig. 11. The good agreement corroborates the fitting procedure chosen. Structural fitting parameters are given in Table 3. $\alpha-\mathrm{MoO}_{3}$ exhibits a strong anisotropic thermal expansion with a pronounced expansion along the $\mathrm{c}$ direction and perpendicular to the $\mathrm{a}, \mathrm{b}$ layers. Therefore, $\alpha$ $\mathrm{MoO}_{3}$ measured at $673 \mathrm{~K}$ in air was used as reference to account for the corresponding changes in the local structure. A comparison of the structural fitting parameters of activated $\mathrm{Mo}_{x} \mathrm{O}_{y}$-VGCNF and $\alpha-\mathrm{MoO}_{3}$ measured at $673 \mathrm{~K}$ (Table 3) shows nearly identical Mo-O and Mo-Mo distances. Similar to the XAFS refinement of as-prepared $\mathrm{Mo}_{x} \mathrm{O}_{y}$-VGCNF, no reliable fitting procedure was obtained for simultaneously varying $\mathrm{CN}$ and $\sigma^{2}$. Hence, only $\sigma^{2}$ were allowed to vary in the refinement while $\mathrm{CN}$ were fixed to bulk values. An alternative approach with varying $\mathrm{CN}$ and fixing $\sigma^{2}$ to bulk values resulted in similar overall fit residual with larger confidence intervals. Because bulk hex$\mathrm{MoO}_{3}$ transforms to $\alpha-\mathrm{MoO}_{3}$ at temperatures above $623 \mathrm{~K}$, no corresponding reference measurements can be performed. However, compared to the thermal treatment of hex- $\mathrm{MoO}_{3}$ supported and stabilized on SBA-15 [9], it can be seen that the characteristic differences between the local structures in hex- $\mathrm{MoO}_{3}$ and $\alpha-\mathrm{MoO}_{3}$ persist at elevated temperatures. Hence, we suggest that the local structure around the Mo centers in activated $\mathrm{Mo}_{x} \mathrm{O}_{y}$-VGCNF is very similar to that of $\alpha-\mathrm{MoO}_{3}$. The structural changes observed during thermal treatment of $\mathrm{Mo}_{x} \mathrm{O}_{y}$-VGCNF under reaction conditions corresponded to a transformation from hexagonal $\mathrm{MoO}_{3}$ to $\alpha-\mathrm{MoO}_{3}$ (Fig. 8). 
Table 3: Type and number $(N)$ of atoms at distance $R$ from the absorbing Mo atom in the local structure of as-prepared $\mathrm{Mo}_{x} \mathrm{O}_{y}-\mathrm{VGCNF}$ (Fig. 4), activated $\mathrm{Mo}_{x} \mathrm{O}_{y}-\mathrm{VGCNF}$ at $673 \mathrm{~K}$ (Fig. 11), and $\alpha-\mathrm{MoO}_{3}$ measured at $673 \mathrm{~K}$. Experimental distances and XAFS disorder parameters $\left(\sigma^{2}\right)$ were obtained from the refinement of a hex- $\mathrm{MoO}_{3}$ model structure to the experimental Mo K edge XAFS FT $\left(\chi(k) * k^{3}\right)\left(k\right.$ range from 3.0 to $14.0 \AA^{-1}, R$ range 0.9-4.0 $\AA, N_{\text {ind }}=24, E_{0}=0 \mathrm{eV}$, fit residual 8.4 for activated $\mathrm{Mo}_{x} \mathrm{O}_{y}-\mathrm{VGCNF}, N_{\text {free }}=11$ ). Subscript C indicates parameters that were correlated in the refinement (same $\Delta R$ with respect to model structure or $\sigma^{2}$ ). Confidence limits correspond to those given in Table 1 .

\begin{tabular}{|c|c|c|c|c|c|c|c|}
\hline \multirow[t]{2}{*}{ Type } & \multirow[t]{2}{*}{$N$} & \multicolumn{2}{|c|}{ As-prep $\mathrm{Mo}_{x} \mathrm{O}_{y}$-VGCNF } & \multicolumn{2}{|c|}{ Act $\mathrm{Mo}_{x} \mathrm{O}_{y}$-VGCNF $(673 \mathrm{~K})$} & \multicolumn{2}{|c|}{$\alpha-\mathrm{MoO}_{3}(673 \mathrm{~K})$} \\
\hline & & $R(\AA)$ & $\sigma^{2}\left(\AA^{2}\right)$ & $R(\AA)$ & $\sigma^{2}\left(\AA^{2}\right)$ & $R(\AA)$ & $\sigma^{2}\left(\AA^{2}\right)$ \\
\hline Mo-O & 1 & 1.69 & 0.00081 & 1.70 & 0.0012 & 1.69 & 0.0031 \\
\hline Mo-O & 1 & $1.75_{c}$ & $0.00081_{\mathrm{c}}$ & $1.75_{\mathrm{c}}$ & $0.0012_{c}$ & $1.75_{\mathrm{c}}$ & $0.0031_{c}$ \\
\hline Mo-O & 2 & 1.97 & 0.0041 & 1.97 & 0.0040 & 1.97 & 0.0023 \\
\hline Mo-O & 1 & $2.21_{c}$ & $0.0041_{c}$ & $2.20_{c}$ & 0.0049 & $2.21_{c}$ & $0.0023_{c}$ \\
\hline Mo-O & 1 & 2.40 & 0.0028 & 2.37 & 0.0029 & 2.38 & 0.0021 \\
\hline Mo-Mo & 2 & 3.37 & 0.0068 & 3.42 & 0.0115 & 3.43 & 0.0083 \\
\hline Mo-Mo & 2 & 3.79 & $0.0068_{c}$ & 3.75 & $0.0115_{c}$ & 3.73 & $0.0083_{c}$ \\
\hline Mo-Mo & 2 & 4.03 & 0.0109 & 4.08 & 0.0147 & 4.10 & 0.0139 \\
\hline
\end{tabular}

\subsection{Catalytic performance of activated MoxOy- VGCNF}

During in situ XAS measurements of temperatureprogrammed treatment of $\mathrm{Mo}_{x} \mathrm{O}_{y}-\mathrm{VGCNF}$ in $3 \%$ propene and $10 \%$ oxygen (Fig. 8), the gas phase composition was continuously monitored by mass spectrometry. Evolution of normalized ion currents of selected masses $(\mathrm{m} / \mathrm{e})$ is depicted in Fig. 12. Onset of catalytic activity is observed at $573 \mathrm{~K}$. Formation of total oxidation product $\mathrm{CO}_{2}(\mathrm{~m} / \mathrm{e} 44)$ and selective oxidation product acrolein $(\mathrm{m} / \mathrm{e} 56)$ at this temperature is typical for molybdenum oxide-based catalyst. At $673 \mathrm{~K}$, the formation of $\mathrm{CO}_{2}$ strongly declined accompanied by formation of acrylic acid (m/e 72). This behavior is atypical because $\mathrm{MoO}_{3}$ catalysts are commonly believed to be inactive for the oxidation of propene to acrylic acid.Additionally, quantitative catalytic measurements were performed at $673 \mathrm{~K}$ in $5 \%$ propene and $5 \%$ oxygen in helium. This reactant ratio was chosen because of specific concentration and mass flow constrains of the GC systems used. The XAS in situ cell was used as reactor. Catalyst and diluent mass were chosen according to the in situ measurements described above. Regular $\alpha-\mathrm{MoO}_{3}$ obtained from thermal decomposition of AHM [8] served as reference compound. The mass of $\alpha-\mathrm{MoO}_{3}$ was adjusted to yield a comparable Mo K edge jump for both catalysts. Conversion of propene on $\mathrm{Mo}_{x} \mathrm{O}_{y}$-VGCNF under these conditions amounted to $9 \%$ compared to $1.4 \%$ on reference $\alpha-\mathrm{MoO}_{3}$. Concentrations of major oxidation products measured in the in situ cell exhaust amounted to $7500 \mathrm{ppm}$ and $700 \mathrm{ppm} \mathrm{CO}_{2}, 920 \mathrm{ppm}$ and $110 \mathrm{ppm}$ acrolein, and $120 \mathrm{ppm}$ and $\sim 1 \mathrm{ppm}$ acrylic acid for $\mathrm{Mo}_{x} \mathrm{O}_{y}$-VGCNF and $\alpha-\mathrm{MoO}_{3}$, respectively. The catalysis data measured confirm that in situ XAS experiments were performed in the desired differential conversion regime. Furthermore, it can be noticed that the $\mathrm{Mo}_{x} \mathrm{O}_{y}$-VGCNF catalyst is much more active per Mo mass than the $\alpha-\mathrm{MoO}_{3}$ catalyst. It is also much more active in the selective oxidation of propene to acrylic acid.

\subsection{Correlations between structure and catalytic performance of activated MoxOy-VGCNF}

Structural transformation of as-prepared hexagonal $\mathrm{Mo}_{x} \mathrm{O}_{y}$-VGCNF to activated $\mathrm{Mo}_{x} \mathrm{O}_{y}$-VGCNF (Fig. 8) resembled the structural evolution of bulk hex- $\mathrm{MoO}_{3}$ under reaction conditions [9]. However, it appears that the resulting $\mathrm{MoO}_{3}-\mathrm{CNF}$ catalyst possessed a distinctly different catalytic behavior. The catalytic performance of $\alpha-\mathrm{MoO}_{3}$ obtained from bulk hex $-\mathrm{MoO}_{3}$ is similar to that of reference $\alpha-\mathrm{MoO}_{3}$ prepared by thermal decomposition of ammonium heptamolybdate. The resulting $\alpha-\mathrm{MoO}_{3}$ is slightly active in selective oxidation of propene to acrolein. The major product, however, is carbon dioxide from total oxidation while no formation of acrylic acid is detected. Conversely, activated $\mathrm{Mo}_{x} \mathrm{O}_{y}$-VGCNF is more selective in the oxidation of propene. Interestingly, it is also more active in selective oxidation of propene to acrylic acid.

Further structure-activity correlations were derived from the in situ EXAFS data shown in Fig. 8. Evolution of the average Mo valence of $\mathrm{Mo}_{x} \mathrm{O}_{y}$-VGCNF during treatment under reaction conditions is depicted in Fig. 12. The average Mo valence was determined from a comparison to reference compounds as described in Ref. In contrast to bulk $\alpha-\mathrm{MoO}_{3}$ [8], $\mathrm{Mo}_{x} \mathrm{O}_{y}$-VGCNF exhibited an increasing average valence at temperatures above $623 \mathrm{~K}$ that coincides with the onset of catalytic activity. Eventually, the Mo centers in the $\mathrm{Mo}_{x} \mathrm{O}_{y}$-VGCNF catalyst are fully oxidized to an average valence of six. Moreover, the increase in average Mo valence is accompanied by an improved selectivity. During hold at $673 \mathrm{~K}$, evolution of $\mathrm{CO}_{2}$ strongly declines while formation of acrylic acid is detected.

Evolution of the local structure around the Mo centers in $\mathrm{Mo}_{x} \mathrm{O}_{y}$-VGCNF during treatment under reaction conditions (Fig. 8) is depicted in Fig. 13 together with evolution of normalized ion currents of acrolein (m/e 56) and acrylic acid ( $\mathrm{m} / \mathrm{e} 72)$. The rapid structural transformation of hex $-\mathrm{MoO}_{3}$ to $\alpha-\mathrm{MoO}_{3}$ supported on VGCNF is readily visible from the characteristic lengthening of the Mo-Mo distance at $\sim 3.4 \AA$ at $\sim 600 \mathrm{~K}$. This rapid transformation coincides with the onset of catalytic activity and formation 

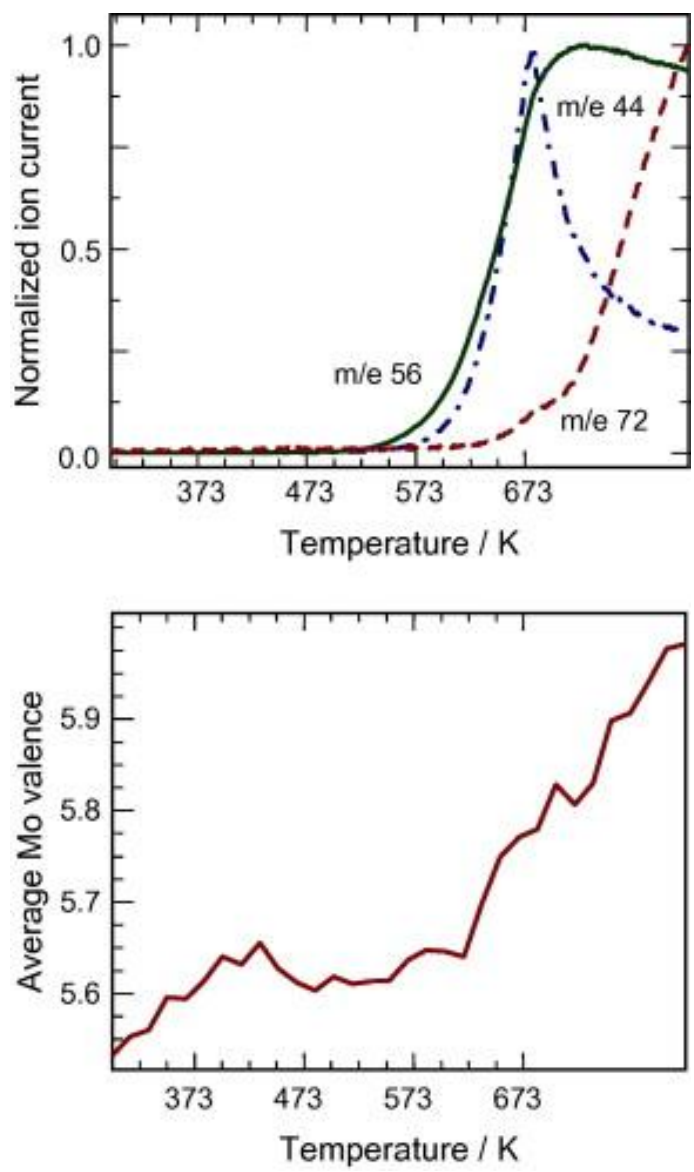

Fig. 12: (Top) evolution of normalized MS ion currents of $\mathrm{CO}_{2}$ (m/e 44, dash-dotted), acrolein (m/e 56, solid), and acrylic acid (m/e 72, dashed) and (bottom) evolution of Mo K edge "while line" and average Mo valence during thermal treatment of $\mathrm{Mo}_{x} \mathrm{O}_{y}$ VGCNF in 3\% propene/10\% oxygen in He (298-673 K, $5 \mathrm{~K} / \mathrm{min}$, hold at $673 \mathrm{~K}$ ).

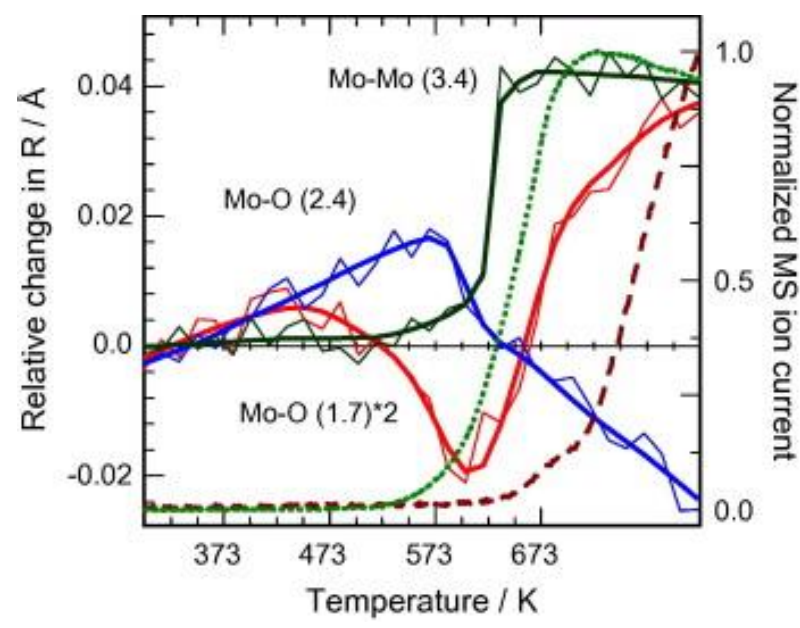

Fig. 13: Evolution of relative change in distance $R$ of selected Mo$\mathrm{O}$ and Mo-Mo distances in local structure of activated $\mathrm{Mo}_{x} \mathrm{O}_{y^{-}}$ VGCNF (Table 2) together with normalized MS ion current of acrolein (m/e 56, dotted) and acrylic acid (m/e 72, dashed) measured during thermal treatment of $\mathrm{Mo}_{x} \mathrm{O}_{y}$-VGCNF in $3 \%$ propene/10\% oxygen in $\mathrm{He}(298-673 \mathrm{~K}, 5 \mathrm{~K} / \mathrm{min}$, hold at $673 \mathrm{~K})$ (Fig. 8). of acrolein and $\mathrm{CO}_{2}$. Oxidation of $\alpha-\mathrm{MoO}_{3}-\mathrm{VGCNF}$ proceeds on a different timescale as can be seen from the slowly increasing average valence (Fig. 12) and slowly changing Mo-O distances at $\sim 2.4$ and $\sim 1.7 \AA$.

\subsection{Isothermal correlation of structure and activ- ity of activated MoxOy-VGCNF at $673 \mathrm{~K}$}

In order to further elucidate and correlate structural changes and catalytic behavior, isothermal switching experiments were performed. Therefore, the gas atmosphere was rapidly switched between reducing (3\% propene) and oxidizing (3\% propene and $10 \%$ oxygen) conditions. Mo K edge XANES spectra were measured with a time resolution of $30 \mathrm{~s}$. No EXAFS scans and, thus, no analysis of the local geometric structure were available at this measuring time. Prior to the switching experiments, the catalyst was treated in $3 \%$ propene at $723 \mathrm{~K}$ resulting in a slight reduction of the catalyst (average valence of $\sim 5.0$ ). Evolution of Mo K edge XANES spectra of activated $\mathrm{Mo}_{x} \mathrm{O}_{y}$-VGCNF during isothermal switching experiments is shown in Fig. 14. The changes visible in the XANES region after $\sim 4$ min correspond to the oxidation of the previously reduced Mo species to mostly $\mathrm{MoO}_{3}$ supported on VGCNF.

The average Mo valence was again calculated from the Mo K edge position as described above. Additionally, the height of the main peak in the Mo K XANES spectrum was determined (Fig. 2). Fig. 15 shows the evolution of the MS ion currents of acrolein, $\mathrm{CO}_{2}$, and acrylic acid during the isothermal switching experiments together with the Mo average valence and XANES peak height (Fig. 10). Changes in peak height are compared to formation of acrolein and $\mathrm{CO}_{2}$, while changes in average valence are compared to the formation of acrylic acid. Apparently, the XANES peak height decreased very rapidly with introduction of oxygen into the reactor. This change corresponds to a rapid structural transformation of a partially reduced $\mathrm{Mo}_{x} \mathrm{O}_{y}$ to $\mathrm{MoO}_{3}$. The formation of $\mathrm{MoO}_{3}$ supported on VGCNF coincided with the onset of catalytic activity, while the rates of acrolein and $\mathrm{CO}_{2}$ formation, and $\mathrm{Mo}_{x} \mathrm{O}_{y}$ oxidation are nearly identical.

Conversely, the average Mo valence exhibited a different time-dependent behavior. A first rapid increase in average valence after introduction of oxygen coincided with the onset of catalytic activity. Subsequently, the reoxidation rate continuously decreased, in contrast to the XANES peak height. The shape of the valence trace resembled solid-state kinetic models with diffusion in the solid as rate-determining step. After the average Mo valence reached a value of $\sim 5.7$, the ion currents of acrolein and $\mathrm{CO}_{2}$ strongly decreased, accompanied by an increase in the production of acrylic acid. An average valence of six corresponding to complete re-oxidation to $\mathrm{MoO}_{3}$ was reached after $\sim 1000 \mathrm{~s}$. Interestingly, evolution of Mo K edge position and peak height appear to correspond to different structural changes in the activated $\mathrm{Mo}_{x} \mathrm{O}_{y}$-VGCNF catalyst. 
While the edge position reflects to average Mo valence and oxidation behavior, the XANES peak height (Fig. 10) is dominated by changes in the local structure around the Mo centers in activated $\mathrm{Mo}_{x} \mathrm{O}_{y}$-VGCNF.

Structural evolution and catalytic behavior of activated $\mathrm{Mo}_{x} \mathrm{O}_{y}$-VGCNF at $673 \mathrm{~K}$ during switching experiments agrees well with the corresponding evolution dedepicted in [Fig. 12] and [Fig. 13]. Under both isothermal and temperature-programmed reaction conditions, formation of acrylic acid is detected. In both experiments, detection of acrylic acid was delayed with respect to the onset of catalysis and accompanied by a decrease in formation of $\mathrm{CO}_{2}$. The latter indicates an increasing selectivity, which in both cases appears to be correlated with an increasing Mo average valence.

Both complete re-oxidation to an average Mo valence of six and formation of acrylic acid have not been observed during switching experiments with bulk $\alpha-\mathrm{MoO}_{3}$. Because of the characteristic defects formed in the threedimensional layer structure of $\alpha-\mathrm{MoO}_{3}$ below $700 \mathrm{~K}$ [7] and [8], the re-oxidation rate under reaction conditions remains lower than the reduction rate. This leads to an average Mo valence lower than six for bulk $\alpha-\mathrm{MoO}_{3}$ under propene oxidation conditions. Accordingly, the partially reduced bulk $\alpha-\mathrm{MoO}_{3}$ is less selective in propene oxidation, and formation of acrylic acid is hardly observed. Conversely, activated $\mathrm{Mo}_{x} \mathrm{O}_{y}$-VGCNF possessed a lower reducibility compared to bulk $\alpha-\mathrm{MoO}_{3}$ accompanied by complete reoxidation to mainly $\mathrm{Mo}(\mathrm{VI})$ centers. It may be assumed that the characteristic shear-defects that form in bulk $\alpha-\mathrm{MoO}_{3}$ under reaction conditions and hinder complete re-oxidation at temperatures below $700 \mathrm{~K}$ do not form in the $\mathrm{MoO}_{3}$ type molybdenum oxide species supported on VGCNF. Mo centers in the supported oxide may exhibit a local structure similar to that of $\alpha-\mathrm{MoO}_{3}$. However, the characteristic twoand three-dimensional layer structure of bulk $\alpha-\mathrm{MoO}_{3}$ may be absent in the supported catalyst. Hence, a different structure forms under reaction conditions, whose reduction and re-oxidation kinetic favor the selective oxidation of propene to acrylic acid.

Similar to supported hexagonal $\mathrm{MoO}_{3}$ on SBA-15 [9] or heteropolyoxo molybdates [26], an improved selectivity correlated with a sufficiently rapid and complete reoxidation to predominantly $\mathrm{Mo}(\mathrm{VI})$ centers. As stated above, the average Mo valence under reaction conditions is not a characteristic of a particular catalyst composition or local structure. It rather results from the characteristic reduction and re-oxidation kinetics of this structure under reaction conditions. Evidently, binary molybdenum oxides are capable of oxidizing propene to acrylic acid. Given favorable structural conditions we have shown that even a catalyst species possessing the local- and medium-range order structure of conventional $\alpha-\mathrm{MoO}_{3}$ may exhibit suitable redox kinetics and corresponding superior catalytic properties. Additional metal centers such as vanadium, niobium, or tungsten are not essential for this functionality, and structural complexity appears more important than chemical complexity.

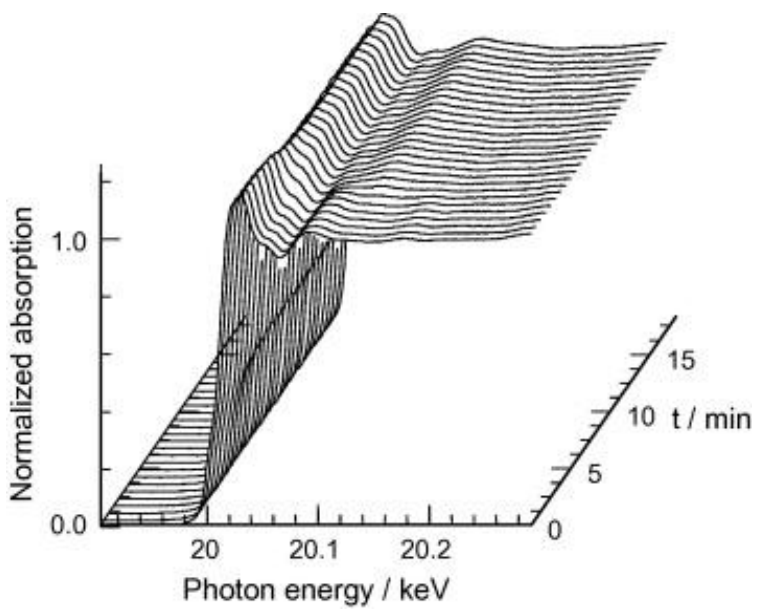

Fig. 15: Evolution of Mo $\mathrm{K}$ edge XANES spectra of activated $\mathrm{Mo}_{x} \mathrm{O}_{y}$-VGCNF measured during isothermal treatment in $3 \%$ propene in He at $673 \mathrm{~K}$. After $\sim 2.5$ min oxygen was switched on and the sample treated in $3 \%$ propene $10 \%$ oxygen in He at $673 \mathrm{~K}$.
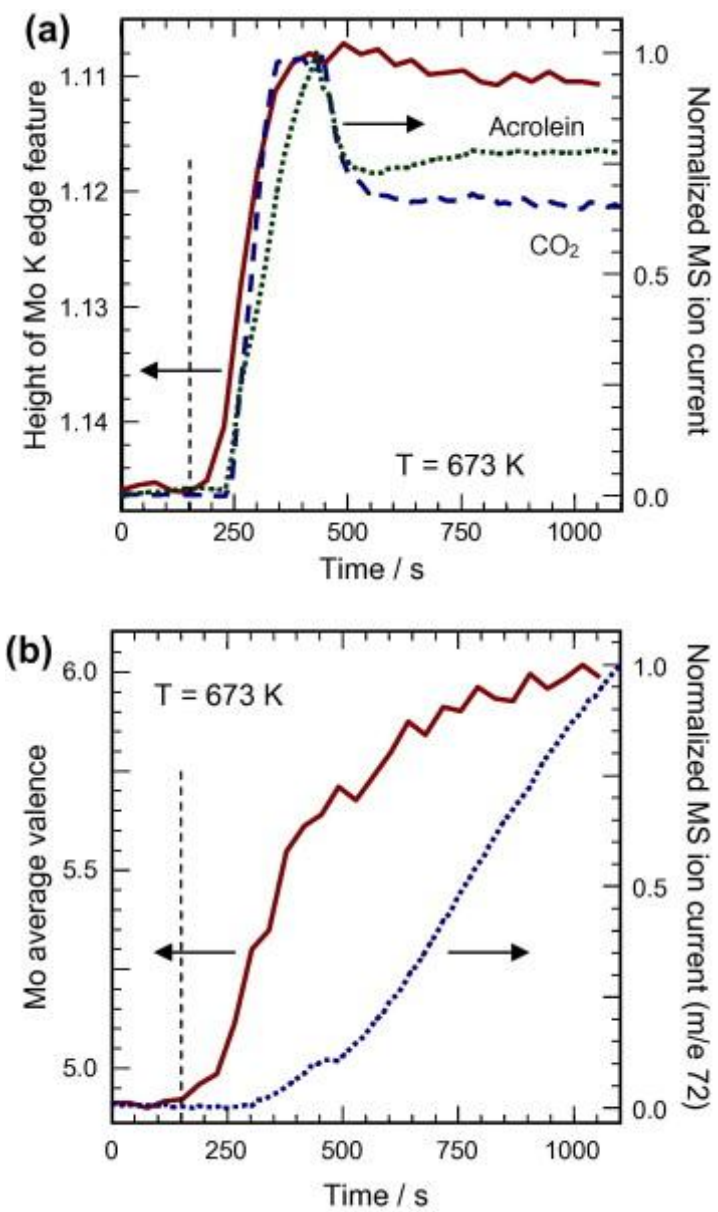

Fig. 16: (a) Evolution of normalized MS ion currents of $\mathrm{CO}_{2}(\mathrm{~m} / \mathrm{e}$ 44, dashed), acrolein (m/e 56, dotted), and Mo K edge peak height (solid) and (b) evolution of normalized MS ion current of acrylic acid (m/e 72, dotted) and Mo average Mo valence (solid) measured during isothermal treatment in $3 \%$ propene in He at $673 \mathrm{~K}$. After $150 \mathrm{~s}$ oxygen was switched on (dashed line) and the sample treated in $3 \%$ propene $/ 10 \%$ oxygen in $\mathrm{He}$ at $673 \mathrm{~K}$. 


\section{Summary}

In situ X-ray absorption spectroscopy under reaction conditions of selective propene oxidation was employed to elucidate the local structure of as-prepared and activated molybdenum oxide supported on carbon nanofibers. The local structure of as-prepared $\mathrm{Mo}_{x} \mathrm{O}_{y}$-VGCNF was very similar to that of hexagonal $\mathrm{MoO}_{3}$. Compared to silicabased supports which may stabilize hex- $\mathrm{MoO}_{3}$ at temperatures above $673 \mathrm{~K}$, the presence of hex- $\mathrm{MoO}_{3}$ on VGCNF results from moderate temperatures $(<623 \mathrm{~K})$ during catalyst preparation. During heat treatment in propene- and oxygen-containing atmosphere, as-prepared $\mathrm{Mo}_{x} \mathrm{O}_{y^{-}}$ VGCNF transforms into activated $\mathrm{Mo}_{x} \mathrm{O}_{y}$-VGCNF above $623 \mathrm{~K}$. The local structure around the Mo centers in activated $\mathrm{Mo}_{x} \mathrm{O}_{y}-\mathrm{VGCNF}$ is similar to that of $\alpha-\mathrm{MoO}_{3}$. A slightly reduced amplitude is indicative of Mo oxide support interaction and small, layer-like $\mathrm{MoO}_{3}$ species supported on VGCNF. Temperature and time-dependent XAS measurements showed a rapid transformation from hex$\mathrm{MoO}_{3}$ to $\alpha-\mathrm{MoO}_{3}$ supported on VGCNF under reaction conditions. Subsequently, the resulting activated $\mathrm{Mo}_{x} \mathrm{O}_{y^{-}}$ VGCNF catalyst exhibited a slowly increasing average

\section{References}

[1] B. Grzybowska-Swierkosz, Topics in Catalysis 2000, 11/12, $23-42$.

[2] R.K. Grasselli, Catalysis Today 1999, 49, 141 - 153.

[3] J. Haber, E. Lalik, Catalysis Today 1997, 33, 119 - 137.

[4] Mars, P., and van Krevelen, D.W., Chem. Ing. Sci. 3, 41 (1954).

[5] L.D. Krenzke, G.W. Keulks, J. Catal. 1980, 61, 316 - 325.

[6] W. Ueda, Y. Moro-Oka, T. Ikawa, J. Catal. 1981, 70, $409-$ 417.

[7] T. Ressler, R.E. Jentoft, J. Wienold, T. Neisius, Journal of Catalysis, 210 (2002) $67-83$.

[8] T. Ressler, J. Wienold, R.E. Jentoft, F. Girgsdies, Eur.J.Inorg.Chem., 2 (2003) 301-312.

[9] T. Ressler, A. Walter, Z.-D. Huang, W. Bensch, J. Catal. 254 (2008) 170-179.

[10] I.E. Wachs, Catal. Today 100 (2005) 79-94.

[11] K. Chen, S. Xie, A.T. Bell, E. Iglesia, J. Catal. 198 (2001) 232-242.

[12] S.H. Taylor, A.J.J. Pollard, Catal. Today 81 (2003) 179-188

[13] C. Hess, J. Catal. 248 (2007) 120-123.

[14] P. Serp, M. Corrias, P. Kalck, Appl. Catal. A 253 (2003) 337.

[15] A. Walter, R. Herbert, C. Hess, T. Ressler, Chemistry Central Journal, accepted. oxidation state. The latter coincided with the formation of acrylic acid, which is hardly detectable during catalysis on regular, binary $\alpha-\mathrm{MoO}_{3}$. Moreover, activated $\mathrm{Mo}_{x} \mathrm{O}_{y^{-}}$ VGCNF is much more active in the selective oxidation of propene compared to $\alpha-\mathrm{MoO}_{3}$. Apparently, the particular local structure of " $\alpha-\mathrm{MoO}_{3}$ "-like molybdenum oxide species supported on CNF permits a complete re-oxidation under reaction conditions in contrast to regular $\alpha-\mathrm{MoO}_{3}$. The correlation between catalytic selectivity and average oxidation state as a result of suitable reduction-oxidation kinetics corroborates the importance of structural complexity rather than chemical complexity.

\section{Acknowledgements}

The Hamburg Synchrotron Radiation Laboratory, HASYLAB, is acknowledged for providing beamtime for this work. The authors acknowledge financial support from the Deutsche Forschungsgemeinschaft, DFG (Cluster of Excellence "Unifying Concepts in Catalysis").

[16] S.R. Bare, T. Ressler, Advances in Catalysis, 52 (2009) 339 465.

[17] J.-P. Tessonnier, D. Rosenthal, T.W. Hansen, C. Hess, M.E. Schuster, R. Blume, F. Girgsdies, N. Pfänder, O. Timpe, D.S. Su, R. Schlögl, Carbon 47 (2009) 1779-1798.

[18] J.-P. Tessonnier, T. W. Hansen, C. Hess, D. S. Su, R. Schlögl, in preparation.

[19] T. Ressler, R.E. Jentoft, J. Wienold, M.M. Günter, O. Timpe, J. Phys. Chem. B 104 (2000) 6360 - 6370.

[20] T. Ressler, J. Synch. Rad. 1998, 5, 118 - 122.

[21] J. J. Rehr, C. H. Booth, F. Bridges, S. I. Zabinsky, Phys. Rev. B 49 (1994) 12347 - 12350.

[22] [22] T. Ressler, S.L. Brock, J. Wong, S.L. Suib, J. Phys. Chem. B 103 (1999) 6407 - 6420.

[23] [http://www.ixasportal.net/ixas/images/ixas_mat/StandardsCr iteria_July25_2000.pdf

[24] Numerical Recipes: The Art of Scientific Computing, Third Edition (2007), Cambridge University Press (www.nr.com).

[25] J. Wienold, R.E. Jentoft, T. Ressler, Eur.J.Inorg.Chem., 6 (2003) 1058-1071.

[26] T. Ressler, O. Timpe, Journal of Catalysis 247 (2007) 231237. 